\title{
Comunicação
}

[Communication]

\section{Referências hematológicas para a jararaca de rabo branco (Bothrops leucurus) recém capturadas da natureza}

\author{
[Hematological references for wild recently-caught white-tailed lancehead (Bothrops leucurus)] \\ K.F. Grego ${ }^{1}$, J.A.S. Alves ${ }^{2}$, L.C. Rameh de Albuquerque ${ }^{1}$, W. Fernandes ${ }^{1}$ \\ ${ }^{1}$ Laboratório de Herpetologia-Instituto Butantan \\ Av. Vital Brasil, 1500 \\ 05503-900 - São Paulo, SP \\ ${ }^{2}$ Universidade Federal de Mato Grosso - Cuiabá, MT
}

O conhecimento dos valores hematológicos normais de determinada espécie é importante para elucidar diagnósticos de enfermidades que acometem os animais, tanto mantidos em cativeiro como nos de vida livre. Estudos hematológicos em répteis são escassos e, ao contrário do que acontece em mamíferos e aves, poucos trabalhos podem ser citados. O número de publicações é ainda menor quando se trata de serpentes peçonhentas brasileiras.

As células comumente encontradas no sangue de serpentes são eritrócitos, trombócitos e leucócitos. Os eritrócitos das serpentes são elípticos e nucleados, sendo as suas formas imaturas, eritroblastos, comumente vistas em pequena quantidade e mais arredondadas, com núcleo maior e citoplasma um pouco basofílico. Hemoparasitos intraeritrocitários, como o Hepatozoon $\mathrm{sp}$, são freqüentemente vistos. Os trombócitos são células nucleadas que variam de tamanho e forma, possuem núcleo central, com cromatina mais homogênea do que a dos eritrócitos, e citoplasma azul pálido e agranular. Os trombócitos têm tendência a se agregar e participam do mecanismo de coagulação.

Como ainda existe polêmica quanto à nomenclatura das células sangüíneas em répteis, a nomenclatura morfológica adotada neste trabalho é a proposta por Alleman et al. (1999). Segundo esse autor, dentre os leucócitos de serpentes, pode-se citar os linfócitos, os azurófilos, os heterófilos e os basófilos. Os eosinófilos são encontrados em quelônios e lagartos, mas a sua presença em serpentes necessita de maiores estudos. Os linfócitos são os leucócitos mais encontrados no sangue das serpentes e são células mononucleares, menores que os eritrócitos. Seu núcleo tem menor padrão de cromatina densa e seu citoplasma é basofílico. O seu aumento na circulação está relacionado a processos inflamatórios, processos de cicatrização, parasitemia e doenças virais. Os azurófilos são o segundo leucócito mais encontrado no sangue de serpentes. Possuem o citoplasma vacuolizado e núcleo central a excêntrico. O seu aumento sugere processos infecciosos crônicos. Os heterófilos são leucócitos eosinofílicos grandes, de núcleo excêntrico e com grânulos citoplasmáticos de esféricos a fusiformes. Podem ser encontrados heterófilos íntegros ou degranulados. $\mathrm{O}$ seu aumento está, geralmente, associado a uma resposta inflamatória ligada a inflamações microbianas e a doenças parasitárias, estresse e neoplasias. Os basófilos são células pequenas e esféricas, com grande número de grânulos basofílicos no seu citoplasma. Sua função em serpentes, provavelmente, é a mesma que nos mamíferos, pois eles possuem imunoglobulinas na superfície e liberam histamina na degranulação. 
Este estudo foi realizado em serpentes peçonhentas da espécie Bothrops leucurus (Família Viperidae), conhecida popularmente como jararaca do rabo branco. Essa espécie é comum na faixa atlântica (Zona da Mata) do Nordeste, desde a Paraíba até o norte do Espírito Santo. Ela habita tanto as áreas urbanas como as rurais, causando acidentes, principalmente no período diurno dos meses de março, maio, junho, setembro e outubro (Lira-da-Silva et al., 2004). Essa espécie, de porte avantajado, pode medir até 170 centímetros de comprimento (Melgarejo, 2003) e alimenta-se de roedores, lagartos, anfíbios, serpentes e aves (Martins et al., 2002).

As amostras de sangue foram colhidas de 29 serpentes, 11 machos (média do comprimento rostro-cloacal (CRC), 75,5 $\pm 9,6 \mathrm{~cm}$, e média do peso, $147 \pm 54,2 \mathrm{~g}$ ) e 18 fêmeas (média do CRC, $85,27 \pm 20,1 \mathrm{~cm}$, e média do peso, $316,87 \pm 160 \mathrm{~g}$ ), clinicamente saudáveis e recém-chegadas da natureza, entre dezembro de 2000 e julho de 2004, provenientes da cidade de Porto Seguro Bahia.

A colheita de sangue foi feita por venopunção da veia caudal, conforme proposto por Frye (1991), valendo-se de seringas plásticas descartáveis. Imediatamente após a colheita foram obtidas extensões sangüíneas para a realização da contagem celular diferencial. A amostra sangüínea foi acondicionada em tubo plástico, contendo anticoagulante heparina $(10 \mu \mathrm{l} / \mathrm{ml}$ de sangue), foi utilizada para determinar os parâmetros hematológicos. As amostras foram mantidas refrigeradas até o momento da realização dos exames.

O hematócrito $(\mathrm{Ht})$ foi determinado pelo método do microematócrito; a hemoglobina foi medida por meio da mistura de $10 \mu 1$ de sangue em $2,5 \mathrm{ml}$ da solução de Drabkin e determinada pela absobância a 540nm e comparada com a da hemoglobina padrão ${ }^{1}$. Foram calculados os índices hematimétricos absolutos como volume corpuscular médio (VCM), hemoglobina corpuscular média (HCM) e concentração hemoglobínica corpuscular média (CHCM). As contagens totais de eritrócitos, leucócitos e trombócitos foram realizadas em uma diluição de sangue 1:200 em solução isotônica de Natt \& Herrick, que permite que os eritrócitos, leucócitos e trombócitos sejam contados, ao mesmo tempo, em câmara de Neubauer. A contagem diferencial de leucócitos e a prevalência de hematozoários foram realizadas em extensão sangüínea corada pelo corante de Rosenfeld e observada com auxílio de microscópio de luz no aumento de 100x.

Os resultados obtidos foram tabulados e suas médias, com seus respectivos desvios padrão foram calculados. $\mathrm{O}$ teste estatístico $\mathrm{t}$ de student foi utilizado para analisar diferenças entre as médias dos machos e das fêmeas.

$\mathrm{Na}$ Tab. 1 apresentam-se os valores médios hematológicos, para fêmeas e machos. Não houve diferença estatística entre machos e fêmeas. A média geral dos resultados para hemoglobina e hematócrito foi de $7,114 \pm 2,48 \mathrm{~g} / \mathrm{dl}$ e $22,30 \pm 5,9 \%$, respectivamente. A média da contagem total de eritrócitos foi de $4,23 \pm 1,32$ celx $10^{5} / \mathrm{mm}^{3}$; da contagem total de leucócitos foi de 8,92 celx $10^{3} / \mathrm{mm}^{3}$; e da contagem total de trombócitos foi de $8,60 \pm 5,9$ cel $\times 10^{3} / \mathrm{mm}^{3}$. A média para volume corpuscular médio (VCM) foi de 567,86fl; de hemoglobina corpuscular média (HCM) de 180,69pg; e de concentração hemoglobínica corpuscular média (CHCM) de 31,85\%.

Na contagem relativa diferencial de leucócitos os valores médios para linfócitos, azurófilos, heterófilos intactos, heterófilos degranulados e basófilos foram, respectivamente, 5,73 celx $10^{3} / \mathrm{mm}^{3}, \quad 1,78 \quad$ celx $10^{3} / \mathrm{mm}^{3}$, 0,57 celx $10^{3} / \mathrm{mm}^{3}, \quad 0,36$ cel $10^{3} \mathrm{~mm}^{3} \quad$ e 0,45 celx $10^{3} / \mathrm{mm}^{3}$.

Foi observada a presença de Hepatozoon sp em $58,6 \%$ dos animais (17/29). Nas fêmeas, 50\% estavam infectadas (9/18) e nos machos, 72,7 \% (8/11). Entre as serpentes parasitadas e não parasitadas, observou-se diferença significativa apenas na contagem relativa dos heterófilos íntegros, isto é, 4,5\% nos animais parasitados e $8,9 \%$ nos não parasitados. Os eritrócitos infectados por Hepatozoon sp. geralmente são maiores que os não infectados.

${ }^{1}$ Laboratório Labtest 
Tabela 1. Valores hematológicos para serpentes da espécie Bothrops leucurus, segundo o sexo

\begin{tabular}{|c|c|c|c|c|}
\hline \multirow[b]{2}{*}{ Parâmetro hematológico } & \multicolumn{2}{|c|}{ Fêmeas } & \multicolumn{2}{|c|}{ Machos } \\
\hline & $\begin{array}{c}\text { Média } \pm \\
\text { desvio-padrão }\end{array}$ & Intervalo & $\begin{array}{c}\text { Média } \pm \\
\text { desvio-padrão }\end{array}$ & Intervalo \\
\hline Hemoglobina (g/dl) & $6,73 \pm 1,97$ & $3,44-10,13$ & $6,91 \pm 2,59$ & $4,3-11,44$ \\
\hline Hematócrito (\%) & $22 \pm 5,694$ & $11-29$ & $23,44 \pm 7,07$ & $15-36$ \\
\hline $\operatorname{VCM}(\mathrm{fl})$ & $615,27 \pm 325,63$ & $306,12-1705,88$ & $503,85 \pm 61,17$ & $395,83-590,16$ \\
\hline HCM (pg) & $195,68 \pm 146,23$ & $88,16-595,88$ & $147,67 \pm 35,47$ & $100,83-200,26$ \\
\hline СHCM (\%) & $29,73 \pm 6,01$ & $22,93-43,47$ & $29,66 \pm 6,21$ & $19,63-35,75$ \\
\hline $\operatorname{CTE}\left(\times 10^{5} / \mathrm{mm}^{3}\right)$ & $402 \pm 146,97$ & $170-660$ & $463,33 \pm 114,12$ & $300-640$ \\
\hline CTT $\left(\times 10^{3} / \mathrm{mm}^{3}\right)$ & $8,17 \pm 4,83$ & $2-17,5$ & $7,5 \pm 3,55$ & $4-14,5$ \\
\hline $\operatorname{CTL}\left(\times 10^{3} / \mathrm{mm}^{3}\right)$ & $7,26 \pm 3,95$ & $0,5-15$ & $11,55 \pm 8,23$ & $2,5-26,5$ \\
\hline Linfócitos $\left(\times 10^{3} / \mathrm{mm}^{3}\right)$ & $4,35 \pm 2,58$ & $0,44-9,28$ & $7,49 \pm 5,56$ & $1,85-15,37$ \\
\hline Azurófilos $\left(\times 10^{3} / \mathrm{mm}^{3}\right)$ & $1,57 \pm 1,28$ & $0,03-5,25$ & $2,36 \pm 2,75$ & $0,07-7,42$ \\
\hline $\begin{array}{l}\text { Heterófilos intactos } \\
\left(\times 10^{3} / \mathrm{mm}^{3}\right)\end{array}$ & $0,56 \pm 0,57$ & $0-1,61$ & $0,64 \pm 0,66$ & $0-1,69$ \\
\hline Heterófilos degranulados $\left(\times 10^{3} / \mathrm{mm}^{3}\right)$ & $0,29 \pm 0,32$ & $0-1,14$ & $0,54 \pm 0,71$ & $0,02-1,85$ \\
\hline Basófilos $\left(\times 10^{3} / \mathrm{mm}^{3}\right)$ & $0,49 \pm 0,63$ & $0-2,17$ & $0,46 \pm 0,31$ & $0,05-0,95$ \\
\hline
\end{tabular}

$\mathrm{VCM}=$ volume corpuscular médio; $\mathrm{HCM}=$ hemoglobina corpuscular média; $\mathrm{CHCM}$ = concentração de hemoglobina corpuscular média; $\mathrm{CTE}=$ contagem total de eritrócitos; $\mathrm{CTT}=$ contagem total de trombócitos; $\mathrm{CTL}=$ contagem total de leucócitos.

O anticoagulante utilizado foi a heparina. Segundo Jacobson (1987), o EDTA pode lisar as células sangüíneas de alguns répteis, embora estudos recentes indiquem o EDTA como anticoagulante adequado para alguns animais da Ordem Squamata (Dotson et al., 1995; Salakij et al., 2002). Como em outras serpentes, os linfócitos foram as células mais comumente observadas (Alleman et al., 1999; Lamirande et al., 1999; Salakij et al., 2002), seguidas pelos azurófilos (Alleman et al., 1999; Salakij et al., 2002). Os basófilos foram as menos freqüentes. $\mathrm{Na}$ maioria dos quelônios e crocodilianos, os heterófilos parecem ser os leucócitos mais observados (Mateo et al., 1984; Montali, 1988; Alleman et al., 1992). Os eosinófilos são comumente observados em crocodilianos e quelônios, mas a sua existência no sangue dos diferentes Squamatas, particularmente as serpentes, é controversa (Montali, 1988; Campbell, 1996; Alleman et al., 1999).

A hematologia deve ser considerada uma avaliação diagnóstica importante para pacientes reptilianos. A informação hematológica é essencial para se reconhecer mudanças no perfil das serpentes enfermas, identificar os tipos de células inflamatórias em tecidos lesionados e entender o papel das diferentes células em infecções agudas e crônicas. Um melhor conhecimento da hematologia de serpentes é imprescindível à medida que se tenta melhorar a qualidade sanitária desses animais, tanto em vida livre como em cativeiro.

Palavras-chave: cobra, Bothrops leucurus, hematologia, hemoparasitos

\section{ABSTRACT}

The hematological values for the specie Bothrops leucurus, recently captured from nature, were determined from blood samples of 29 snakes (11 males and 18 females). The performed hematological tests were: total red blood cell count (TRBCC), total white blood cell count (TWBCC), total trombocyte blood cell count (TTBCC); packed cell volume (PCV); hemoglobin content; and mean corpuscular volume $(\mathrm{MCV})$, mean corpuscular hemoglobin $(\mathrm{MCH})$ and mean corpuscular hemoglobin concentration (MCHC). The mean values for TRBCC was 4.23 cells $x 10^{5} / \mathrm{mm}^{3}$, for TWRCC was $8.92 \mathrm{cells} \times 10^{3} / \mathrm{mm}^{3}$ and for TTBCC was 8.60 cells $10^{3} / \mathrm{mm}^{3}$. The mean for packed cell volume was $22.3 \%$. The intraerythrocytic hemoparasite Hepatozoon sp was found on $58.6 \%$ of the studied animals.

Keywords: snake, Bothrops leucurus, hematology, hemoparasites 


\section{REFERÊNCIAS BIBLIOGRÁFICAS}

ALLEMAN, A. R.; JACOBSON, E.R.; RASKIN, R.E. Morphologic and cytochemical characteristics of blood cells from the desert tortoise (Gopherus agassizii). Am. J. Vet. Res., v.53, p.1645-1651, 1992.

ALLEMAN, A.R.; JACOBSON, E.R.; RASKIN, R.E. Morphologic, cytochemical staining, and ultrastuctural characteristics of blood cells from eastern diamondback rattlesnakes (Crotalus adamanteus). Am. J. Vet. Res., v.60, p.507-514, 1999.

CAMPBELL, T.W. Clinical pathology. In: MADER D.R. (Ed.). Reptile medicine and surgery. Philadelphia: W.B. Saunders, 1996. p.248-257.

DOTSON, T.K.; RAMSAY, E.C.; BOUNOUS, D.I. A color atlas of blood cells of the yellow rat snake. Compendium, v.17, p. 1013 - 1016, 1995.

FRYE, F.L. Hematolgy as applied to clinical reptile medicine In: FRYE, F.L. (Ed.). Reptile care-an atlas of diseases and treatments, 1991. v.1, p.209-277.

JACOBSON, E.R. Reptiles exotic pet medicine. Vet. Clinic. N. Am., v.17, p.1203-1225, 1987.

LAMIRANDE, E.W.; BRATTHAUER, A.D.; FISHER, D.C. et al. Reference hematology and plasma chemistry values of Brown tree snakes (Boiga irregularis). J. Zoo Wild. Med., v.30, p.516-520, 1999.

LIRA-DA-SILVA, R.M.; MISE, Y.F.; NASCIMENTO, A.A.A. et al. Fatores ambientais e antrópicos determinantes na distribuição das serpentes de importância médica no estado da Bahia, Brasil. . In: Seminário de Pesquisa da Faculdade de Tecnologia e Ciências, 2004, Salvador. Anais ... Salvador, 2004. p. 5477.

MARTINS, M.; MARQUES, O.A.V. ; SAZIMA, I. Ecological and phylogenetics correlates of feeding habits in neotropical pitvipers of the genus Bothrops. In: SCHUETT, G.; HÖGGREN, M.; GREENE, H.W. (Org.). Biology of the vipers. Carmel, 2002. p.1-22.

MATEO, M.R.; ROBERTS, E.D.; ENRIGHT, F.M. Morphological, cytochemical, and functional studies of peripheral blood cells of young healthy American alligator (Alligator mississipiensis). Am. J. Vet. Res., v.45, p.10461053, 1984.

MELGAREJO, A.R. Serpentes peçonhentas do Brasil. In: CARDOSO, J.L.C.; FRANÇA, F.O.S.; FAN, H.W. et al. (Org.). Animais peçonhentos no Brasil: Biologia, clínica e terapêutica dos acidentes. São Paulo, 2003. v. 1, p. 33-61.

MONTALI, R.L. Comparative pathology of inflammation in the higher vertebrates (reptiles, birds, and mammals). J. Comp. Pathol., v.99, p.1-26,1988.

SALAKIJ, C.; SALAKJI, J.; APIBAL, S. et al. Hematology, morphology, cytochemical staining, and ultrastructural characteristics of blood cells in king cobras (Ophiophagus Hannah). Vet. Clin. Pathol., v.31, p.116-126, 2002. 